\title{
Osteoarthritis and articular chondrocalcinosis in the elderly
}

\author{
EDWARD WILKINS, ${ }^{1}$ PAUL DIEPPE, ${ }^{2}$ PETER MADDISON,${ }^{2}$ AND \\ GORDON EVISON'
}

From the ${ }^{2}$ Royal National Hospital for Rheumatic Diseases, Bath, and 'St Martin's Hospital, Bath

SUMMARY One hundred consecutive admissions to an acute geriatric unit were examined for clinical and radiographic evidence of osteoarthritis (OA) and articular chondrocalcinosis (ACC). Thirty-four patients had ACC. This was age related, the prevalence rising from $15 \%$ in patients aged $65-74$ years to $44 \%$ in patients over 84 years. The commonly involved joints were the knee $(25 \%)$, pubic symphysis (15\%), and wrist (9\%). No other aetiological factors predisposing to ACC were found. Of the 25 patients with ACC in the knee 7 had no symptoms or signs and no radiographic evidence of $\mathrm{OA}$ at that site. However, the combination of ACC and radiographic OA was characterised by an increase in clinical joint disease. Features of inflammation (joint swelling and joint line tenderness) involving the knee, wrist, and elbow were particularly common in ACC. It is concluded that ACC is common in the elderly and is associated with an increased incidence of joint disease.

The relationship between intra-articular deposition of calcium pyrophosphate dihydrate crystals and arthritis was first described in 1962 by McCarty et al. ${ }^{1}$ The original description was of a monoarticular acute arthritis, and because of similarities with urate arthropathy the condition was termed pseudogout. Recently it has been suggested that pyrophosphate deposition can be associated with a number of differing patterns of joint disease, on occasions mimicking both osteoarthritis and rheumatoid arthritis. ${ }^{2}$

The radiographic appearance of linear calcification of joint cartilage as described by Zitnan and $\mathrm{Sitaj}^{3}$ is one sign of pyrophosphate crystal deposition. Such calcification (chrondrocalcinosis) is common in the elderly, but its significance is unknown. It is often found in asymptomatic joints, suggesting th? $t$ articular chondrocalcinosis (ACC) can be a function of aging and not a marker of joint disease.

The present study was designed to assess the prevalence of radiographic ACC in the elderly and to relate such calcification to clinical and radiographic evidence of joint disease.

\section{Patients and methods}

The study was approved by the local ethical com-

Accepted for publication 5 May 1982.

Correspondence to Dr E. Wilkins, Diagnostic Centre, Royal United Hospital, Bath. mittee. One hundred and twenty consecutive admissions to an acute geriatric unit were studied, the age, sex, and reason for admission noted, and verbal consent obtained before inclusion in the study.

Clinical details. A general examination of the musculoskeletal system was followed by a detailed examination of the hands, wrists, and knees. The findings were tabulated by a single observer and a simple grading system was employed: joint pain, swelling, and crepitus were graded 0 -none, 1-mild, 2-moderate, and 3-severe. Joint warmth and effusion were scored as present or absent. Joint deformity at the knee was defined as valgus or varus deformity of more than $10^{\circ}$ or a fixed deformity of more than $5^{\circ}$; a restriction of arc movement at the wrist to below $60^{\circ}$ was also considered abnormal.

Radiographic details. The radiographs were taken on either a GEC D8/150 with Dynamax tube (focal spot size $1.0 \mathrm{~mm}$ ) or a GEC Linotome with a Dynamax tube (focal spot sizes $0.6 \mathrm{~mm}$ or $1.3 \mathrm{~mm}$ ). Anteroposterior and lateral views of both knees were taken on Ilford Rapid R film, average exposure 10 $\mathrm{mAs}$ at $57-60 \mathrm{kV}$. An anteroposterior view of the pelvis was taken on Kodak X-O-Mat RP-X RPI with an average exposure of $36 \mathrm{mAs}$ at $72 \mathrm{kV}$ and an AP view of both hands and wrists on Ilfex 90 film, average exposure $30 \mathrm{mAs}$ at $60 \mathrm{kV}$.

The radiographs were assessed independently by the radiologist (G.E.), who had no knowledge of the 


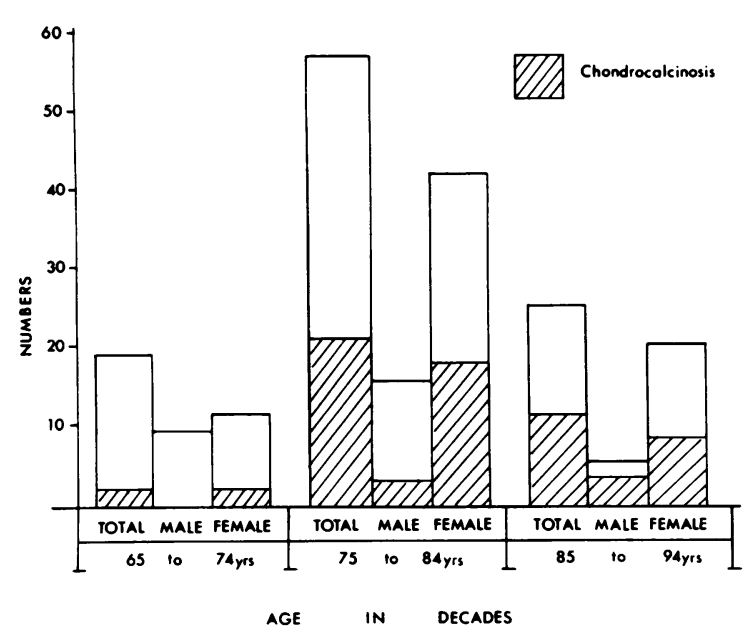

Fig. 1 Prevalence of articular chondrocalcinosis.

clinical data, and by the clinicians. Agreement on grading, after the initial analysis, was obtained in $85 \%$ of the cases. The remaining $15 \%$ were then subjected to a combined assessment to obtain a final agreed grade. The presence of linear shadows of calcific density in joint cartilage (ACC) was recorded as unilateral, bilateral, linear, stippled, dense, or hazy, and graded 1-4 (1-visible with magnifying glass, 2-faint but visible with naked eye, 3-moderate, 4-dense). Radiographic evidence of osteoarthritis was graded mild, moderate, or severe in accordance with the criteria laid down by Kellgren and Lawrence. ${ }^{4}$ Other investigations included full blood count, blood calcium, phosphate, alkaline phosphatase, serum creatinine, and thyroid function tests.

\section{Results}

One hundred and twenty consecutive admissions were studied over a 10 -week period. Complete data were obtained on 100 patients. There were 3 general categories of admission; $32 \%$ were referrals from other specialties for rehabilitation, mainly from strokes (14 patients) and limb fractures (13 patients); $29 \%$ were referred by their general practitioners because of the patients' failure to cope with living in the community (19 for psychiatric reasons and 17 with chronic 'physical' disability). The remainder (49\%) were admitted for investigation and treatment of 'general' medical conditions such as heart failure (8 patients), anaemia ( 7 patients), and weight loss ( 7 patients). Ages ranged from 65 to 97 years with a mean of 79.4 years (SD 6.67). There were 31 males and 69 females (male:female ratio of $1: 2 \cdot 2$ ).

Thirty-four patients had ACC. There was a clear relationship to increase in age; the prevalence rose from $15 \%$ ( 3 out of 20 ) in patients aged between 65 and 74 years, to $36 \%$ (20 out of 55) between 75 and 84 years, and to $44 \%$ (11 out of 25 ) in patients above 84 years (Fig. 1).

Most of the subjects with ACC (25 out of 34 ) had involvement of the knee joint. Fibrocartilage was more commonly affected than hyaline; the lateral fibrocartilage being most frequently involved (18 out of 25 ).

Fifteen patients had ACC at the pubic symphysis. Ten had involvement at the wrist, all had triangular ligament ACC, half had bilateral involvement. Involvement at more than one site was common: 15 subjects had ACC at the knee and pubic symphysis, while 9 out of the 10 subjects with ACC at the wrist also had knee involvement. Six subjects had involvement of knee, wrist, and pubic symphysis (Table 1). The character of the chondrocalcinosis varied with the site of involvement. Articular hyaline cartilage calcification was generally linear and that of the menisci hazy or dense. A faint opacity in the hyaline cartilage at the medial half of the lateral femoral condyle was in some cases the only sign of calcification. Anteroposterior radiography of both knees gave the best single view for detecting the presence of ACC.

General metabolic disorders that have been implicated in pyrophosphate crystal deposition ${ }^{5}{ }^{6}$ were not apparent, and aging alone appeared to be the main aetiological factor. The small number of patients who had diabetes mellitus (4) or thyroid disease (10) was

\section{Table 1 Distribution of articular chondrocalcinosis}

\begin{tabular}{lrll}
\hline Site & Numbers & Unilateral & Bilateral \\
\hline Hands & & & \\
$\quad$ IP joint & 1 & 0 & 1 \\
MCP joint & 4 & 2 & 2 \\
$\quad$ Intracarpal joint & 3 & 1 & 2 \\
$\quad$ Total & 8 & 5 & 3 \\
Wrists & & & \\
$\quad$ Triangular & 10 & 4 & 6 \\
$\quad$ Radiocarpal & 6 & 3 & 3 \\
$\quad$ Total & 10 & 5 & 5 \\
Knees & & & \\
$\quad$ Hyaline: & & & \\
$\quad$ Femur & 14 & 6 & 3 \\
$\quad$ Tibia & 5 & 2 & 3 \\
Fibrocartilage: & & & 10 \\
$\quad$ Medial & 14 & 4 & 12 \\
$\quad$ Lateral & 18 & 6 & - \\
$\quad$ Total & 25 & 9 & 2 \\
Symphysis & 15 & - & 2 \\
Hips & & & 4 \\
$\quad$ Hyaline & 3 & 1 & \\
$\quad$ Glenoid & 2 & 0 & \\
Total & 5 & 1 & \\
\hline
\end{tabular}


Table 2 Articular chondrocalcinosis: relationship to clinical and laboratory data

\begin{tabular}{|c|c|c|}
\hline & Chondro. group & No chondro. group \\
\hline Total in each group & 34 & 66 \\
\hline Mean age & $81 \cdot 4( \pm 6 \cdot 2)$ & $79 \cdot 0( \pm 6 \cdot 9)$ \\
\hline Male to female ratio & $7: 27(1: 3 \cdot 8)$ & $21: 25(1: 2 \cdot 5)$ \\
\hline \multicolumn{3}{|l|}{ Medical history of: } \\
\hline Diabetes mellitus & 2 & 2 \\
\hline Thyrotoxicosis & 2 & 3 \\
\hline Myxoedema & 2 & 3 \\
\hline Osteomalacia & 1 & 4 \\
\hline \multicolumn{3}{|l|}{ Drug history of: } \\
\hline Steroids & 1 & 1 \\
\hline \multicolumn{3}{|l|}{ Anti-inflammatory } \\
\hline drugs & 9 & 19 \\
\hline Diuretics & 14 & 24 \\
\hline \multicolumn{3}{|l|}{$\begin{array}{l}\text { Laboratory data: } \\
\text { (Mean values and SD) }\end{array}$} \\
\hline $\mathrm{Hgb}$ & $12 \cdot 1( \pm 1 \cdot 8)$ & $12 \cdot 4( \pm 2 \cdot 0)$ \\
\hline Blood viscosity & $1 \cdot 77( \pm 0 \cdot 17)$ & $1.73( \pm 0.4)$ \\
\hline \multicolumn{3}{|l|}{ Blood: } \\
\hline Calcium & $2 \cdot 30( \pm 0 \cdot 21)$ & $2 \cdot 31( \pm 0 \cdot 15)$ \\
\hline \multicolumn{3}{|l|}{ Alkaline } \\
\hline phosphatase & $111 \cdot 0( \pm 32)$ & $111 \cdot 0( \pm 41)$ \\
\hline Phosphate & $1 \cdot 3( \pm 0 \cdot 20)$ & $1.08( \pm 0.24)$ \\
\hline Creatinine & $106 \cdot 0( \pm 46)$ & $93 \cdot 0( \pm 38)$ \\
\hline Thyroid function & $117 \cdot 0( \pm 30)$ & $124 \cdot 0( \pm 36)$ \\
\hline
\end{tabular}

not sufficient to allow comment on any possible relationship between these conditions and $\mathrm{ACC}{ }^{78}$ Laboratory measurements in patients with and without ACC are shown in Table 2; there were no significant differences.

Most subjects had some clinical evidence of joint disease. The hands were involved in $90 \%$ of subjects, with swelling and/or deformity of the carpometacarpal joint the commonest abnormality (68\%). $62 \%$ had abnormal knee joints; $31 \%$ had valgus, varus, or flexion deformity, and $20 \%$ had joint tenderness. $37 \%$ had abnormal elbow joints, the majority with fixed flexion abnormalities. $29 \%$ had abnormalities at the wrist, mainly restriction of movement. Sixteen patients had pain and loss of movement at the shoulder.

The prevalence of clinical disease of the large joints was greater in patients with ACC than in those without (Table 3).

The relationship between the clinical assessment of joint disease and radiological grading of OA at the knee is shown in Table 4. OA changes were seen in $48 \%$ of all knees $(62 \%$ of patients with ACC and $41 \%$ of those without). It was also noted that 6 out of 8 patients with ACC and mild OA had clinical abnormalities, compared with 4 out of 15 patients with mild OA and no ACC.

The nature of the relationship between joint disease and $\mathrm{ACC}$ was further illustrated in the 9 subjects

Table 3 Articular chondrocalcinosis and clinical joint disease

\begin{tabular}{|c|c|c|c|c|c|c|c|c|}
\hline & \multicolumn{4}{|c|}{ Subjects with ACC (n=34) } & \multicolumn{4}{|c|}{ Subjects without $A C C(n=66)$} \\
\hline & \multicolumn{4}{|c|}{ Presence of joint disease } & \multicolumn{4}{|c|}{ Presence of joint disease } \\
\hline & Pain & Swelling & $\begin{array}{l}\text { Loss of } \\
\text { movement }\end{array}$ & $\begin{array}{l}\text { No. with } \\
\text { joint } \\
\text { abnormality }\end{array}$ & Pain & Swelling & $\begin{array}{l}\text { Loss of } \\
\text { movement }\end{array}$ & $\begin{array}{l}\text { No. with } \\
\text { joint } \\
\text { abnormality }\end{array}$ \\
\hline \multicolumn{9}{|c|}{ Wrist: } \\
\hline $\mathbf{R}$ & 3 & 7 & 9 & \multirow[t]{2}{*}{$15(57 \%)^{*}$} & 6 & 7 & 15 & \multirow[t]{2}{*}{$14(25 \%)^{*}$} \\
\hline $\mathbf{L}$ & 2 & 4 & 4 & & 6 & 6 & 11 & \\
\hline \multicolumn{9}{|c|}{ Elbow: } \\
\hline $\mathbf{R}$ & 7 & 8 & 12 & \multirow[t]{2}{*}{$18(53 \%)^{* *}$} & 2 & 3 & 13 & \multirow[t]{2}{*}{$19(36 \%)^{* *}$} \\
\hline $\mathbf{L}$ & 3 & 2 & 7 & & 3 & 4 & 15 & \\
\hline \multicolumn{9}{|c|}{ Shoulder: } \\
\hline $\mathbf{R}$ & 5 & 3 & 6 & \multirow[t]{2}{*}{$8(25 \%)$} & 5 & 1 & 4 & \multirow[t]{2}{*}{$8(12 \%)$} \\
\hline $\mathbf{L}$ & 4 & 4 & 5 & & 2 & 2 & 2 & \\
\hline \multicolumn{9}{|c|}{ Knee: } \\
\hline $\mathbf{R}$ & 14 & 18 & 9 & \multirow[t]{2}{*}{$23(67 \%)$} & 16 & 27 & 22 & \multirow[t]{2}{*}{$39(59 \%)$} \\
\hline $\mathbf{L}$ & 10 & 16 & 7 & & 17 & 26 & 21 & \\
\hline \multicolumn{9}{|l|}{ Hip: } \\
\hline $\mathbf{R}$ & 2 & Excluded & 23 & \multirow[t]{2}{*}{$26(83 \%)$} & 6 & Excluded & 42 & \multirow[t]{2}{*}{$42(75 \%)$} \\
\hline $\mathbf{L}$ & 2 & Excluded & 26 & & 4 & Excluded & 40 & \\
\hline
\end{tabular}

Joint abnormalities due to fracture excluded.

${ }^{*} \mathrm{p}=0.006 .{ }^{* *} \mathrm{p}=0.012$.

Statistical method: The $\chi^{2}$ test was used to evaluate the probability that subjects with ACC and joint disease were from the same population as those with joint disease and no ACC (difference is significant with $p$ values $\leqslant 0.05$ ). 
Table 4 Clinical joint disease, radiological $O A$ and $A C C$ at the knee

\begin{tabular}{|c|c|c|c|c|c|c|c|}
\hline & & \multicolumn{2}{|c|}{$\begin{array}{l}\text { Joint tenderness } \\
\text { (Grade 2-3) }\end{array}$} & \multicolumn{2}{|c|}{$\begin{array}{l}\text { Joint swelling } \\
\text { (Grade 2-3) }\end{array}$} & \multicolumn{2}{|c|}{ Flex. deformity } \\
\hline & & With ACC & No ACC & With ACC & No ACC & With $A C C$ & No $A C C$ \\
\hline $\begin{array}{l}\text { Mild radiographic } \mathrm{OA} \\
\text { Number with } A C C-8 \\
\text { without } A C C-15\end{array}$ & $\begin{array}{l}\mathbf{R} \\
\mathbf{L}\end{array}$ & $\begin{array}{l}4(50 \%) \\
2(25 \%)\end{array}$ & $\begin{array}{l}2(13 \%) \\
1(7 \%)\end{array}$ & $\begin{array}{l}4(50 \%) \\
2(50 \%)\end{array}$ & $\begin{array}{l}3(20 \%) \\
2(13 \%)\end{array}$ & $\begin{array}{l}2(25 \%) \\
4(50 \%)\end{array}$ & $\begin{array}{l}2(13 \%) \\
5(33 \%)\end{array}$ \\
\hline $\begin{array}{c}\text { Moderate and severe } \\
\text { radiographic } \mathrm{OA} \\
\text { Number with } A C C-4 \\
\text { without } A C C-11\end{array}$ & $\begin{array}{l}\mathbf{R} \\
\mathbf{L}\end{array}$ & $\begin{array}{l}1(25 \%) \\
1(25 \%)\end{array}$ & $\begin{array}{l}3(27 \%) \\
3(27 \%)\end{array}$ & $\begin{array}{l}3(75 \%) \\
2(50 \%)\end{array}$ & $\begin{array}{l}5(45 \%) \\
6(55 \%)\end{array}$ & $\begin{array}{l}2(50 \%) \\
2(50 \%)\end{array}$ & $\begin{array}{l}7(64 \%) \\
6(55 \%)\end{array}$ \\
\hline $\begin{array}{l}\text { No radiographic } \mathrm{OA} \\
\text { Number with } A C C-13 \\
\text { without } A C C-13\end{array}$ & $\begin{array}{l}\mathbf{R} \\
\mathbf{L}\end{array}$ & $\begin{array}{l}2(15 \%) \\
2(15 \%)\end{array}$ & $\begin{array}{l}4(10 \%) \\
2(5 \%)\end{array}$ & 0 & $\begin{array}{l}5(12 \%) \\
3(8 \%)\end{array}$ & $1(8 \%)$ & $\begin{array}{l}6(15 \%) \\
5(13 \%)\end{array}$ \\
\hline
\end{tabular}

Nine patients with ACC in joints other than the knee not included. One patient with seropositive rheumatoid arthritis not included.

who had unilateral ACC at the knee. Six had clinical and radiographic evidence of joint disease, 4 had bilateral disease with abnormalities most marked on the side with ACC, one patient had joint disease on the side opposite to the site of ACC, while the remaining patient had disease at the site of calcification with a normal joint the other side.

\section{Discussion}

Radiographically detectable intra-articular calcification was first described by Pearson and Davin in $1921 .^{9}$ However, its relationship to arthritis remained unrecognised until the work of Zitnan and Sitaj in $1958 .{ }^{10}$ They described an arthritis associated with punctate and linear radiodensities in hyaline and fibrocartilage, and termed such abnormalities articular chondrocalcinosis.

In 1962 McCarty, Kohn, and Faires ${ }^{1}$ described the pseudogout syndrome, that is, arthritis, articular chondrocalcinosis, and the presence of calcium pyrophosphate dihydrate crystals in synovial fluid. More recently it has been shown that calcium crystals other than pyrophosphates can cause ACC, but linear deposits in hyaline cartilage and meniscal calcification are usually due to deposits of calcium pyrophosphate dihydrate. ${ }^{11}$ In view of the characteristic radiographic pattern seen in most of our subjects we can assume that their ACC was related to pyrophosphate, although for ethical reasons we were unable to obtain crystalographic data on the calcified tissues.

Information relating ACC to clinical and radiographic evidence of joint disease in the elderly is sparse.

Bocher et al. ${ }^{12}$ in 1965 studied the radiographs of
450 patients. Most of these were knee radiographs from files of local hospitals and little clinical data were available. However, they did include 100 patients randomly selected from a local Jewish home for the elderly. Ten patients had ACC, and 8 of these had significant clinical and radiographic evidence of joint disease. Ellman and Levin in $1975^{13}$ studied 58 residents of a Jewish home for the elderly, average age 83 , and they used Kodak type $M$ film to achieve maximum sensitivity. The overall prevalence of ACC was $\mathbf{2 7} \cdot \mathbf{6 \%}$. Clinical examination was performed on all subjects and there appeared to be an increase in varus deformity at the knee, and in pain and deformity at the wrist in patients with ACC. Pritchard and Jessop in $1977,,^{14}$ as part of their study on chondrocalcinosis in hyperparathyroid patients, looked at the knee $x$-rays of 100 elderly patients and found 11 with ACC. All patients had calcification in all 4 menisci, and there was little radiological evidence of joint disease; a clinical examination was not performed.

Ellman and colleagues have recently published 2 more articles on the prevalence of chondrocalcinosis in the elderly and its relationship to joint disease. ${ }^{1516}$ They found a high incidence of radiological chondrocalcinosis, related to age, and more narrowing of the joint space on nonweight bearing films in those with ACC than those without. However, as in the present study, chondrocalcinosis without significant joint disease was also seen.

In the present study of 100 consecutive patients admitted to a geriatric unit 34 had articular chondrocalcinosis. This is a surprisingly high figure but is similar to the findings of Ellman and Levin. The prevalence of ACC increased in a linear fashion with aging. This not only confirms the importance of aging in the aetiology of ACC, but also stresses the importance of expressing such data in terms of decades 
rather than in 'the elderly'. Radiographic techniques and materials adopted for use in this study were selected to achieve maximum sensitivity in the detection of calcium pyrophosphate deposition. Nevertheless, it is likely that radiography can detect only the more obvious ACC and that the $34 \%$ may be an underestimation of the true prevalence.

None of our subjects had hypercalcaemia, only 4 had diabetes mellitus, 3 had myxoedema, and 2 were thyrotoxic. There was no obvious relationship between ACC and diabetes mellitus or thyroid disease, and apart from aging no other aetiological factors emerged.

The relationship between ACC and joint disease in the elderly population studied was not simple. Overall there was an undoubted increase in clinical joint disease in patients with ACC, and yet some patients with florid ACC had normal joints, and conversely others with obvious clinical and radiological evidence of joint disease had no ACC.

There was also a lack of correlation between clinical and radiological grading of joint disease at the knee. This anomaly was apparent in 2 groups of subjects. The first was a group of 5 with ACC but no evidence of radiological OA; they had considerable (grade 1-11) joint tenderness, swelling, and flexion deformity. The second was a group of 8 subjects with mild $\mathrm{OA}$ and ACC. In this group joint tenderness and swelling and the number with flexion deformity was much greater than expected, either from the appearance of the knee radiographs or in comparison with patients who had mild OA but no ACC.

Patients with OA and ACC often presented with involvement of the elbow, shoulder, wrist, and knee; flexion deformity at the elbow seemed particularly characteristic.

The distribution of ACC and associated arthritis seen in our elderly patients was in many cases similar to that seen in chronic pyrophosphate arthropathy, though the progressive and severe joint destruction usually seen in the latter was not so apparent.

The part played by intra-articular crystal deposition in the aetiology of osteoarthritis ${ }^{17} 18$ is still unclear. The result of our study suggests that traditional 'chicken and egg' concept is an oversimplification. We would postulate that intra-articular crystal deposition is in most cases secondary to age-related changes in cartilage. Osteoarthritis can develop independently, is related to aging, but is also dependent on other factors. However, in the presence of OA, intra-articular crystal deposition acts as an additional stimulus to the inflammatory response.

We thank Drs David Wright, Bruno Kasteliz, and Michael Rowe for allowing us to study their patients; Dr Francis Duck for his help with the statistical interpretation; the nursing, radiographic, and portering staff at St Martin's Hospital; and Mrs Sue Willis and Miss Fiona Davies for their help in the preparation of the manuscript.

Acknowledgment is also made to the Bath Area Medical Research Trust for a research grant.

\section{References}

1 McCarty D J, Kohn N N, Faires J S. The significance of calcium phosphate crystals in the synovial fluid of arthritis patients: the 'pseudo-gout syndrome'. I. Clinical aspects. Ann Intern Med 1962; 56: 711-37.

2 Rheumatology Section, Department of Medicine, the Medical College of Wisconsin. Bull Rheum Dis 1974; 25: 804-9.

3 Zitnan D, Sitaj S. Mnohopocetna familiarha kalcifaciz artikularynch chrupiek. Bratisl Lek Listy 1958; 38: 217-28.

4 Kellgren J H, Lawrence J S. Radiological assessment of osteoarthrosis. Ann Rheum Dis 1957; 16: 494-502.

5 Bywaters E G L, Dixon A St J, Scott J T. Joint lesions of hyperparathyroidism. Ann Rheum Dis 1963; 22: 171-87.

6 Hamilton E, Williams R, Barlow K A, Smith P M. The arthropathy of idiopathic haemochromatosis. $Q \mathrm{~J}$ Med 1968; 37: 171-82.

7 Alexandef G M, Dieppe P A, Doherty M, Scott D G. Pyrophosphate arthropathy: a study of metabolic associations and laboratory data. Ann Rheum Dis 1982; 41: 377-81.

8 McCarty D J. Contributions on crystal deposition disease-calcium pyrophosphate. Modern Trends in Rheumatology. London: Butterworth, 1966: 287-302.

9 Pearson K, Davin A G. On the sesamoids of the knee joint. Biometrica 1921; 13: 121-2.

10 Zitnan D, Sitaj S. Calcifications multiples du cartilage articulaire. Ninth International Congress on Rheumatic Diseases, 1957; 2: 291.

11 Dieppe $\mathbf{P}$ A. New knowledge of chondrocalcinosis. J Clin Pathol 1978; 31 suppl 12: 214-22.

12 Bocher J, Mankin H J, Berk R N. The prevalence of calcified meniscal cartilage in elderly persons. $N$ Engl J Med 1965; 272: 1093.

13 Ellman H M, Levin B. Chondrocalcinosis in elderly persons Arthritis Rheum 1975; 18: 43-7.

14 Pritchard M H, Jessop J D. Chondrocalcinosis in primary hyperparathyroidism. Ann Rheum Dis 1977; 36: 146-51.

15 Ellman M H, Brown M L, Levin B. Prevalence of knee chondrocalcinosis in hospital and clinic patients aged 50 or older. J Am Geriatr Soc 1981; 29: 189-92.

16 Ellman M H, Brown M L, Levin B. Narrowing of the knee joint space in patients with pseudogout. Ann Rheum Dis 1981; 40: 34-36.

17 Editorial. Crystals in joints. Lancet 1980; i: 1006-7.

18 Dieppe P A. Milwaukee shoulder. $\mathrm{Br}$ Med J 1981; 283: 1488-9. 